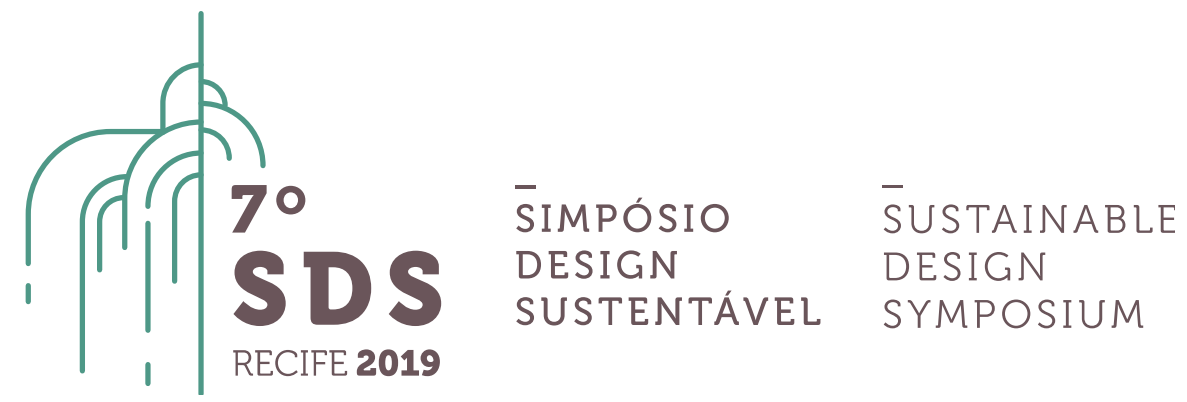

\title{
Design para o Comportamento Sustentável: cocriação de mapas conceituais
}

\author{
Valkiria Pedri Fialkowski ${ }^{1}$ e Aguinaldo dos Santos ${ }^{2}$ \\ ${ }^{1}$ Universidade Federal do Paraná, Núcleo de Design \& Sustentabilidade, val.pedri@gmail.com \\ ${ }^{4}$ Universidade Federal do Paraná, Núcleo de Design \& Sustentabilidade, asantos@ufpr.br
}

Resumo. $O$ presente artigo tem a intenção de relatar um processo de aprendizagem em design com a intenção de fomentar o comportamento sustentável. Para a realização deste, buscou-se embasar e nivelar o entendimento sob a ótica de alguns subtemas de interesse do grupo de pesquisa que conduziu esta experiência, como Comportamento, Ciência dos Dados, Business Analytics, lot e Smart Cities. Partindo dos subtemas citados, o objetivo foi o de incentivar uma reflexão sobre como o designer pode promover $o$ comportamento sustentável no futuro. O método Design Science Research, aqui usado, permitiu com que um grupo de profissionais e estudantes discutissem $e$ construíssem resultados, por meio de revisões gráficas de síntese. A discussão aponta a relevância do tema conjuntamente com seus subtemas, tanto no cenário atual como principalmente no cenário futuro.

Palavras-chave. Design para o Comportamento Sustentável. Sustentabilidade. RGS. Design Science Research. Business Analytics. Smart Cities.

\section{Introdução}

Com o aumento da população e todas as suas atividades, o planeta vem sofrendo uma série de mudanças como escassez de recursos, alteração nos ciclos da natureza e mudanças climáticas abruptas. Estas mudanças impactam em toda a sociedade desde nas questões ambientais como também econômicas e sociais. O conceito de sustentabilidade emerge destas mudanças demandando o desenvolvimento de estratégias que permitam mitigar ou eliminar os impactos derivados do consumo (VEZZOLI, 2018).

Segundo Vezzoli (2018) o conceito de Design como orientado a prover forma a artefatos está ligado diretamente ao paradigma que considera a possibilidade do crescimento ilimitado da produção. No entanto, a redução dos limites de resiliência do planeta tem demonstrado a inviabilidade deste paradigma (MARGOLIN, 2008 apud VEZZOLI, 2018, p.18). Neste contexto, o conceito do desenvolvimento sustentável é endereçado não somente aos limites e impactos biofísicos presentes mas, também, aos impactos no provimento de bem estar para as gerações futuras (CECHIN, 2010 apud VEZZOLI, 2018). 
Uma das estratégias para reduzir ou mitigar os impactos do consumo consiste da aplicação dos métodos e ferramentas associados ao Design para o Comportamento Sustentável (Design for Sustainable Behaviour (DfSB) (BHAMRA et al., 2011). Usualmente o DfSB busca induzir ou motivar o usuário a adotar padrões de consumo mais sustentáveis através de intervenções que vão desde medidas coercitivas até soluções que dependem integralmente da adesão voluntárias do usuário.

Associado ao tema do DfSB está a emergente utilização de dados da internet para compreender comportamentos e hábitos e, também, desenvolver soluções que possibilitem alterar ou reforçar estes comportamentos. Esta prática insere-se no contexto da Era dos Dados. Esta Era ocorre em um cenário onde o mundo da informação mudou radicalmente, transformando-se em um universo de dados digitais dos mais variados formatos. 0 volume de informações produzidas e compartilhadas é tão grande que os métodos tradicionais usados para processá-las não são mais adequados. Desta maneira há uma corrida na indústria de TIC para o desenvolvimento de técnicas e ferramentas capazes de encontrar insights úteis. Termos emergentes como Big Data, Business Analytics (BA), Business Intelligence (BI), Internet das Coisas (IoT), Inteligência Artificial vem sendo utilizados cada vez com mais frequência no âmbito do Design (PRIOR, 2019). O fluxo de informação na web vem possibilitando empresas a transformar dados em ativos, empregando técnicas e métodos para analisá-los, transformando-os em insights relevantes (MJV, 2019).

Apesar do prospecto positivo destas novas tecnologias, Petrini e Pozzebon (2009) alertam que avançamos na visão de que os métodos e ferramentas de Business Intelligence têm um importante papel, mas ainda não bem explorado, de ajudar as organizações a implementar e monitorar o desenvolvimento sustentável. Manzini e Vezzoli (2011) apesar de não tratarem diretamente do assunto relativo aos dados, também apontam a mesma constatação relativas ao cenário futuro, afirmando que há "dois fenômenos fundamentais que colocam em tensão a sociedade contemporânea: a emergência dos limites ambientais e os processos de globalização econômica e cultural ligados à difusão das tecnologias de informação e comunicação" (MANZINI, VEZZOLI, 2011, p. 43). Dados são a matéria prima básica para sistemas de inteligência, tanto para análises individuais como até para aplicação no contexto das Smart Cities (BATTY et al., 2012).

A integração dos métodos e ferramentas associados a dados da internet com os métodos e ferramentas associados à sustentabilidade pode contribuir para mudanças na direção do comportamento sustentável. Muniz e Santos (2015 apud WNDEL, 2014) corroboram esta afirmação ao argumentar que "projetar para a mudança de comportamento integra a pesquisa comportamental, o desenvolvimento pragmático do produto e uma rigorosa análise de dados" (MUNIZ, SANTOS, 2015 apud WENDEL, 2014, p. 59).

O tema representa ainda uma lacuna a ser explorada (PETRINI, POZZEBON, 2009; PETRINNI, 2006). Assim, este artigo se propõe a revisar as interseções teóricas entre Sistemas de Inteligência e Sustentabilidade. Apesar do aumento substancial do número de estudos, quando tomados em conjunto, estão praticamente ausentes da literatura, representando uma lacuna a ser explorada

A coleta de dados foi realizado em um workshop realizado junto a acadêmicos e profissionais de design. A técnica de coleta de dados principal foram as Revisões Gráficas de Síntese (RGSs) resultantes deste workshop, tendo sido aplicado conceitos teóricos de design para o comportamento sustentável atrelado a temas como Comportamento, Smart Cities e loT e Data Science. A partir dessa experiência, e com alicerce da revisão bibliográfica, objetiva-se entender como o designer pode estar preparado para promover o comportamento sustentável no futuro através de Big Data.

\section{Design para o Comportamento Sustentável na Era dos Dados}




\subsection{Design para o Comportamento Sustentável}

A maneira como os consumidores interagem com os produtos pode produzir impactos ambientais, para produtos que consomem energia em uso, por exemplo, o consumo energético é determinado principalmente pelo comportamento (BHAMRA et al., 2011). Por esta razão, os pesquisadores de design começaram a explorar o papel do design influenciar o comportamento do usuário e posteriormente desenvolver abordagens, ferramentas e diretrizes que se concentram no design para um comportamento sustentável (CESCHIN, GAZIULUSOY, 2016; BHAMRA et al., 2011).

As abordagens para o comportamento sustentável em design são construídas a partir de várias teorias de mudança de comportamento. Porém, como observado por Niedderer et al. (NIEDDERER et al., 2014 apud CESCHIN, GAZIULUSOY, 2016) existem muitos modelos diferentes para abordagens de mudança de comportamento, pois também existem muitos modelos de mudança de comportamento nas ciências sociais. Especificamente, o modelo de Design for Sustainable Behavior desenvolvido na Universidade de Loughborough (BHAMRA et al., 2011; LILLEY, 2009), adotado neste artigo, baseia-se na economia comportamental propondo um conjunto de estratégias de intervenção de design baseadas em informar, capacitar, fornecer feedback, recompensar e restringir. Segundo Bhamra et al. (2011) o DfSB é uma atividade de design emergente da sustentabilidade que visa reduzir o impacto ambiental e social, moderando como os usuários interagem com produtos e/ou serviços. Esta abordagem da sustentabilidade consiste em construir soluções (geralmente encontrada na literatura como "produtos") que tanto possuem bom design quanto são comportamentalmente efetivos. Isto significa que são produtos que ajudam as pessoas a mudar o próprio comporta mento. O objetivo é auxiliar as pessoas a fazer coisas que elas querem fazer, mas que ainda não tenham conseguido (MUNIZ, SANTOS, 2015).

Como exemplos de produtos que alteram o comportamento temos o termostato da marca Nest, como citado por Muniz e Santos (2015). O produto possui um sistema que registra as temperaturas habituais dos usuários para automaticamente provê-las no momento apropriado. Isso permite uma redução energética e beneficia o meio ambiente. Outro exemplo refere-se ao projeto das novas cédulas de real. As cédulas possuem tamanhos diferentes de acordo com o valor monetário que possuem. Isso fez com que se atingisse o objetivo comportamental de que as cédulas menores circulassem mais no mercado, uma vez que elas são menores, com dimensões mais adequadas ao tamanho das carteiras e bolsos dos usuários. Consequentemente, as cédulas maiores têm menos circulação, porque não cabem na carteira (MUNIZ, SANTOS, 2015).

Dentre às diversas limitações do DfSB que Ceschin e Gaziulusoy (2016) apontam, destacase aqui as implicações éticas, a falta de métricas para medir o efeito e evidencias de estratégias. Existe uma preocupação sobre o quanto os designers e empresas têm o direito de conduzir o comportamento do usuário. Brahma et al. (2011) acrescentam que existem alguns estudos que abordam esta lacuna, mas suas próprias pesquisas têm procurado focar no assunto utilizando-se de estudos que exploram tecnologia e ética em outros campos disciplinares.

\subsection{Ciência dos Dados, Business Analytics, Smart Cities e Design}

Os novos métodos e ferramentas para coleta de dados constituem em uma mistura entre as expertises de Tecnologia da informação e Comunicação (TIC), matemática, gestão da informação, estatística e administração, dentre outras. É um universo de estudos que transforma vasta quantidade de dados em importantes direcionadores para a tomada de decisão, gerando valor para as empresas e novos modelos de negócios. Os fatores críticos na Era dos Dados são a coleta, análise e disseminação de informações com intuito de melhorar posição competitiva da organização e aprimorar suas entregas. Neste cenário, é imperativo que as organizações convertam os dados em efetiva inteligência no apoio a ações e decisões, passível de acesso no momento certo para uso no processo de tomada de decisão. Neste sentido, o propósito da 
Inteligência é obter valor real a partir de dados e informações (LÓPEZ-ROBLES et al., 2019).

Quanto aos termos da temática a revisão bibliográfica mostrou vários estudos que descrevem a coexistência de termos como Inteligência de Mercado, Inteligência Tecnológica, Inteligência Financeira, Inteligência Organizacional e Corporate Intelligence, Competitive Intelligence, Business Intelligence, Competitor Intelligence, Strategic Intelligence, e Competitive Intelligence. Verifica-se o uso e a coexistência de vários termos similares, de acordo com a abordagem de cada disciplina, (marketing, tecnologia, estratégia, negócios, ciência e etc.), com objetivos e significados semelhantes (FIALKOWSKI, 2019; LÓPEZ-ROBLES et al., 2019; LUCAS et al., 2016; STRAUSS et al., 2012). Embora se observe uma variedade ampla de termos, as ferramentas tecnológicas de gerenciamento de dados podem ser separadas em dois grupos com objetivos diferentes, como também Petrini e Pozzebon (2009) utilizam. O Quadro 1 a seguir detalha essas abordagens.

Quadro 1 - Abordagens das ferramentas tecnológicas para gerenciamento de dados.

\begin{tabular}{lll} 
& Abordagem Tecnológica & Abordagem Administrativa \\
\hline i) Definição & $\begin{array}{l}\text { São ferramentas e infraestrutura } \\
\text { tecnológicas e estatísticas que } \\
\text { apoiamo armazenamento e análise } \\
\text { de informação. }\end{array}$ & $\begin{array}{l}\text { O processo em que os dados internos e externos da } \\
\text { empresa são integrados para gerar informação pertinente } \\
\text { (indicadores, dashboards, relatórios) para o processo de } \\
\text { tomada de decisão. }\end{array}$ \\
\hline $\begin{array}{ll}\text { ii) Foco das } \\
\text { atividades }\end{array}$ & $\begin{array}{l}\text { O foco está nas tecnologias que } \\
\text { permitem a gravação, recuperação, } \\
\text { mineração, manipulação e análise } \\
\text { dos dados e informação, }\end{array}$ & $\begin{array}{l}\text { O foco está na obtenção de informações rel evantes } \\
\text { empresa que possam a poiar o processo decisório e } \\
\text { estratégico. }\end{array}$ \\
\hline $\begin{array}{l}\text { iii) Termos } \\
\text { vizinhos e } \\
\text { ferramentas } \\
\text { para apoiar estando o processo. } \\
\text { abordagem }\end{array}$ & $\begin{array}{l}\text { Data Warehouse, Data Mining, } \\
\text { Data base, Data Mart, Inteligência } \\
\text { Realidade Aumentada. }\end{array}$ & $\begin{array}{l}\text { Business Analytics, Business Intelligence, Competitive } \\
\text { Intelligence, Competitor intelligence, Enterprise reporting, } \\
\text { Intelligence analysis, Market intelligence, Strategic early } \\
\text { warning, Technological Intelligence, Enterprise reporting, } \\
\text { Intelligence analysis, Market intelligence, Strategic early } \\
\text { warning. }\end{array}$ \\
\hline
\end{tabular}

Fonte: os autores com base em López-Robles et al. (2019), LUCAS et al. (2016) e Petrini e Pozzebon (2009)

Seguindo na abordagem administrativa, o trabalho de Scherer et al., (2016) nos ajuda a entender que o Business Analytics (BA) está focado em gerar informação para a tomada de decisão, identificando padrões ou criando modelos de decisão matemáticos a partir de um conjunto determinado de dados. Porém, BA pode ir além por meio das mais modernas tecnologias como Machine Learning, podendo ser classificado como descritivo ou preditivo. A empresa pode criar valor através da segmentação de clientes ou avaliação de desempenho de produtos (SCHERER et al., 2016).

Associado ao termo Business Analytics (e BigData, Machine Learning, Inteligência Aritificial, etc.) estão as ações voltadas à implementação de Smart Cities. Caragliu et al. (2011, p. 70 apud ANDERLE et al., 2013) definem Smart Cities como uma cidade onde se investe em capital humano e social e se utiliza da infraestrutura de TIC como combustível para um crescimento econômico sustentável e uma melhora de qualidade de vida, uma boa gestão de recursos naturais através de um governança participativa. É um ambiente interativo, ainda que possua um ambiente físico onde as TICs "desaparecem" à medida que se tornam embutidas nos artefatos físicos e nos ambientes do dia a dia (ANDERLE et al., 2013).

O conceito de cidade inteligente surgiu durante a última década a partir de diversas ideias sobre como as tecnologias de informação e comunicação podem melhorar a funcionamento das 
cidades, aumentar sua eficiência e melhorar sua competitividade. O objetivo é o de proporcionar novas maneiras em que os problemas de pobreza, privação social e ambiente precário podem ser sanados. Para tal resultado é necessário coordenar e integrar tecnologias que até agora foram desenvolvidas separadamente, mas têm sinergias claras em sua operação (BATTY et al., 2012).

As Cidades inteligentes são frequentemente representadas como constelações de instrumentos/artefatos/soluções que estão conectados através de múltiplas redes que fornecem dados contínuos sobre os movimentos de pessoas e materiais que ajudam a entender os fluxos e até a forma física e social da cidade. No entanto, as cidades só podem ser inteligentes se houver capacidade de integrar e sintetizar esses dados para algum propósito, como formas de melhorar a eficiência, equidade, sustentabilidade e qualidade de vida (BATTY et al., 2012).

As tecnologias que podem ser utilizadas neste contexto incluem todo tipo de sensores e reconhecimentos nos espaços urbanos, acoplados às onipresença dos smartphones com GPS e wearables, além de recursos computacionais na nuvem, permitindo que seja possível automatizar as cidades. O processamento e análise de grande volume de dados exige a integração dos dados por meio de Big Data (BATTY et al., 2012). Deste ponto de vista tecnológico, a questão mais relevante consiste na não interoperabilidade das diversas tecnologias atualmente utilizadas nos empreendimentos urbanos. A este respeito, a visão da loT pode tornar-se o alicerce para realizar uma plataforma unificada de TIC de escala urbana (ANDERLE et al., 2013; BATTY et al., 2012).

O termo Internet das Coisas (IoT Internet of Things), é uma expressão utilizada para descrever a mudança de um modelo de interação tecnológica, no qual as pessoas passaram a interagir com objetos. Estes objetos também possuem capacidade de comunicação entre si a partir de sensores incorporados e compartilhados, usando a internet. A loT pode ser vista como um cruzamento de diversas tecnologias, as quais se complementam para a viabilização da integração dos objetos entre os ambientes físico e virtual. O processo envolve a colaboração entre os vários campos do conhecimento (ROSENMANN et al., 2017). Ao conectar objetos com diferentes recursos a uma rede, potencializa-se o surgimento de novas aplicações. Os objetos, ao promoverem comunicação entre usuários com os dispositivos, possibilitam não somente um aumento na facilidade e qualidade de vida destes, como também a coleta de dados e monitoramento dos mesmos. Desta forma, podemos entender que o seu uso tem influenciado o cotidiano tanto do indivíduo quanto dos negócios (ROSENMANN et al., 2017; SCIAMANA et al., 2018) e cidades. Assim pode-se perceber o quanto os temas Smart Cities e as tecnologias relacionadas a ela, estão intimamente ligadas ao conceito de sustentabilidade, reforçando a importância de se estabelecer uma conexão de caráter teórico entre os temas.

\section{Método}

A pesquisa realizada é qualitativa de caráter exploratório e de natureza aplicada. $O$ método adotado é o Design Science Research (DSR) que se apoia na tradição do próprio design, onde a ideia que prevalece é a de desenvolvimento de um artefato. Neste sentido artefato é entendido como tudo que não é natural, com diferentes níveis de tangibilidade, podendo ser um novo produto, serviço ou sistema, ou mesmo um constructo, modelo, método, instanciação ou design preposition (SANTOS, 2018; DRESCH et al., 2015). No presente trabalho, o intuito é que a DSR recomende um delineamento sobre como o designer pode promover o comportamento sustentável no futuro. Por conseguinte, o resultado obtido são design prepositons, ou seja, contribuições teóricas genéricas para o desenvolvimento de soluções para uma determinada classe de problemas (VAN AKEN, 2011 apud DRESCH et al., 2015; SANTOS, PEREZ, 2018).

O processo de realização de uma pesquisa em Design Science inicia-se com a compreensão do problema de forma integral ou parcial mesmo, uma vez que o próprio artefato resultante pode ajudar a refinar o problema e iniciar novo ciclo. Em seguida há o desenvolvimento do artefato com 
geração de alternativas, seleção e elaboração e, por fim, a avaliação (SANTOS, 2018). O Quadro 2 a seguir ilustra o processo do DSR e as ferramentas escolhidas para cada fase do presente trabalho.

Quadro 2 - Etapas do método de DSR e ferramentas adotadas.

\begin{tabular}{ll}
\hline Fases da DSR & Ferramenta utilizada \\
\hline $\begin{array}{l}\text { i) Compreensão do } \\
\text { problema }\end{array}$ & $\begin{array}{l}\text { Revisão bibliográfica narrativa, a fim de elucidar os principais conceitos dentro do tema } \\
\text { design para o comportamento sustentável e seus temas satélites. }\end{array}$ \\
\hline $\begin{array}{ll}\text { ii) Desenvolvimento } \\
\text { do artefato }\end{array}$ & $\begin{array}{l}\text { Revisões gráficas de síntese (RGS) como ferramenta colaborativa promissora no contexto } \\
\text { de ensino e aprendizagem em disciplinas de pós-graduação em Design e outras áreas. }\end{array}$ \\
\hline iii) Avaliação & $\begin{array}{l}\text { Triangulação da estrutura teórica com o resultado das RGSs e a visão dos estudantes e } \\
\text { profissionais de design que participaram do workshop. }\end{array}$ \\
\hline
\end{tabular}

Fonte: os autores (2019)

Para a fase da compreensão do problema, foi feito um levantamento de dados primários por meio de uma revisão bibliográfica narrativa, a fim de elucidar os principais conceitos dentro do tema design para o comportamento sustentável. Também foi procurada a teoria pertinente a cada subtema, considerados satélites do tema principal e delimitados conforme o interesse do grupo de pesquisa: Comportamento, Ciência dos Dados, Business Analytics, lot e Smart Cities. A procura não foi do tipo sistemática porque buscou-se neste momento apenas familiaridade com o problema. A própria DSR preconiza que o aprofundamento pode ser parcial inicialmente e acontecer mais a fundo como resultado do artefato desenvolvido (SANTOS, PEREZ, 2018). Este conteúdo foi realizado com buscas em artigos, livros, dissertações e teses, assim como sites e blogs. 0 arcabouço teórico foi apresentado na seção anterior, de fundamentação teórica.

Para a fase de desenvolvimento do artefato utilizaram-se de revisões gráficas de síntese (RGS). A escolha da mesma se justifica porque é considerada uma ferramenta colaborativa promissora no contexto de ensino e aprendizagem em disciplinas de pós-graduação em Design e outras áreas (BUENO, PADOVANI, 2017; PADOVANI, 2012). As RGSs consistem em artefatos visíveis bidimensionais e estáticos, criados com o objetivo de exteriorizar ideias e fortalecendo o raciocínio baseado no modelo visual (AINSWORTH et al., 2011 apud BUENO, PADOVANI, 2017). É uma linguagem visual, de aparência lógica ou metafórica, que se utiliza em geral de representação esquemática e pictórica, como ícones, sketches, diagramas, gráficos, mapas de rota, mapas conceituais, mapas mentais, facilitações gráficas, entre outros. Assim, como já comentado, as RGSs foram geradas por um grupo de acadêmicos e profissionais de design a partir da teoria apresentada pelo grupo de pesquisa. Este resultado configura o artefato procurado a partir do método do DSR. Para a última fase da DSR, de avaliação do processo e dos artefatos produzidos, foi realizada de maneira qualitativa, com base na estrutura teórica contraposta com a percepção dos grupo de acadêmicos e profissionais de design que participaram da confecção das RGSs.

\section{Resultados \& Análise}

\subsection{Contexto}

A realização deste estudo deu-se por meio de um workshop presencial realizado com 24 pessoas, acadêmicos e profissionais de design. O convite foi aberto à comunidade e os interessados se inscreveram no site destinado para tal. O título do evento foi: "O Design para o Comportamento Sustentável em Foco - Workshop para Cocriação de Mapas Conceituais de DfSB". Por se tratar de um evento realizado pelo Núcleo de Design e Sustentabilidade e pela própria chamada do evento, inscreveram-se profissionais e empreendedores da área de marketing digital, gastronomia e design, designers de produto, gráfico e usabilidade, além de estudantes da pós- 
graduação de diversas instituições da cidade. Os participantes presentes assinaram termo de autorização de uso de imagem e texto a ser destinada para compor o conteúdo de possíveis produções intelectuais de titularidade dos pesquisadores. A atividade foi organizada e moderada por um grupo de estudos composto por 5 pessoas todos pós-graduandos, sendo três do mestrado e dois do doutorado. O grupo ainda convidou uma doutora em design, como palestrante externa, para apresentar o conceito de DfSB. O foco de pesquisa destes facilitadores tornaram-se os subtemas, ou temas satélites como denominados para este trabalho. O workshop foi dividido em três momentos: exposição, discussão em conjunto ou equipe e conclusão. O momento da exposição foi quando os facilitadores e convidada conduziram uma apresentação teórica para nivelar o conhecimento de todos no que é pertinente ao tema principal e a cada tema satélite, este conhecimento foi exposto na seção de fundamentação teórica deste artigo. No segundo momento do workshop, foi feita a discussão em equipe e construção das RGSs. Em seguida, na fase de conclusão, as RGSs elaboradas foram apresentadas e discutidas perante todo o grupo. Estes resultados são melhor explanados a seguir.

\subsection{Desenvolvimento dos Artefatos}

Nesta fase do workshop os participantes tiveram em torno de 1,5h para discutir os conceitos teóricos vistos, contrapô-los com sua realidade profissional e acadêmica e gerar as RGSs de maneira colaborativa. Os participantes foram divididos em 3 grupos. Os facilitadores acompanharam os grupos participando das discussões e respondendo às dúvidas e fazendo esclarecimentos, quando solicitados. Foram disponibilizados materiais de papelaria como papéis, canetas hidro cor, tesoura, cola e etc., para a criação das RGSs. Também foi disponibilizado um coffe-break para deixar os participantes mais à vontade e estimular a interação. Após a fase de desenvolvimento, cada equipe teve dez minutos para apresentar sua RGS e mais cinco minutos para discutir a mesma perante as percepções do grupo.

A primeira RGS apresentada consta na Figura 1 a seguir. Na realidade foi um grupo de três RGSs complementares, como também pode-se observar na referida Figura. O grupo começou refletido sobre as cidades inteligentes com foco na sustentabilidade. Veem o designer como a pessoa que tem o lado crítico, e que "pode assumir um papel de agente transformador", como comentado. Apesar de que pontuam que "a habilidade de se identificar uma oportunidade é mais difícil que a proposição da própria solução em si". Isto explica a importância dada ao big data que pode ser usado para iniciar e apoiar políticas para as cidades (inteligentes ou não) e comunidades. O designer neste processo ajuda a fazer políticas que favoreçam o comportamento sustentável e tudo isso antecede o desenho do artefato isoladamente.

Figura 1 - RGS do grupo 1.
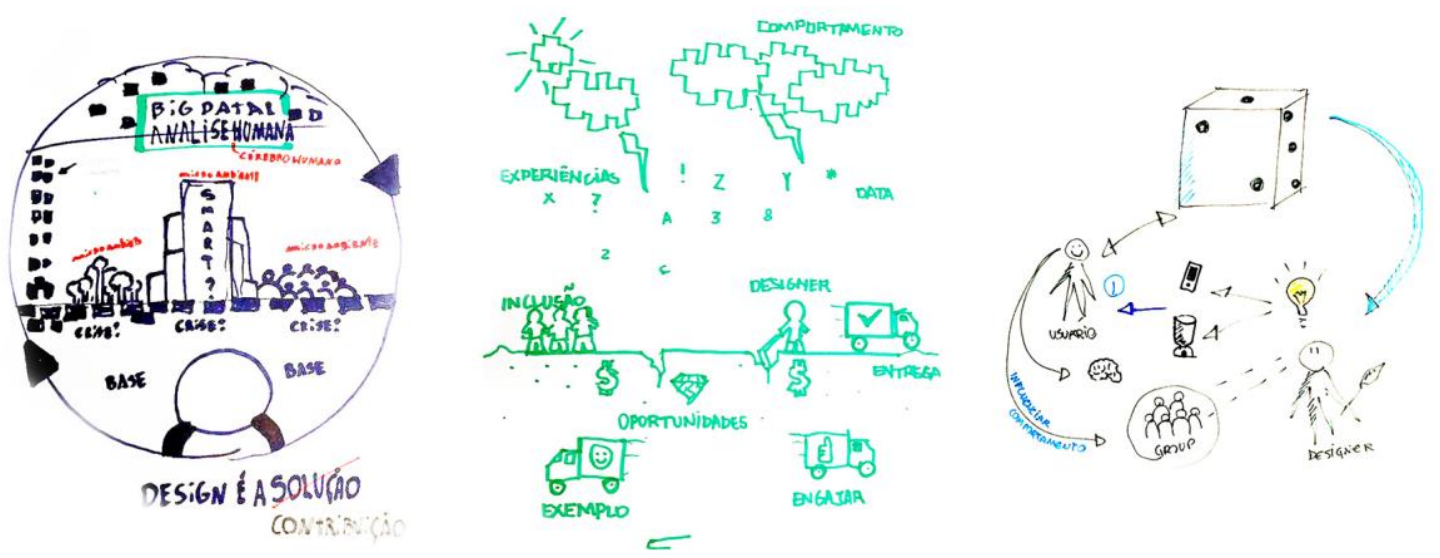

Fonte: participantes do workshop (2019) 
Quanto ao aspecto tecnológico, por um lado enxergam o Big Data monitorando e sendo alimentado de dados constantemente e, por outro, entendem que é necessário ter o designer identificando problemas em alguma comunidade ou cidade. Defendem que o ideal seria o designer se apoiar nestes dados gerados para entender estes problemas e retornar dados sensibilizando a comunidade com respeito a sustentabilidade, de maneira cíclica e também ética.

A segunda RGS desenvolvida consta na Figura 2 a seguir e foi embasada no desenho de cenário sob o ponto de vista da construção de uma persona. Pensou-se no tipo de comportamento da mesma, pontuando que a relação das pessoas com a sustentabilidade varia conforme a natureza da solução, ou seja, uma pessoa pode ser mais sustentável na sua relação com a alimentação, mas menos sustentável em relação ao seu processo de deslocamento, por exemplo.

Figura 2 - RGS do grupo 2

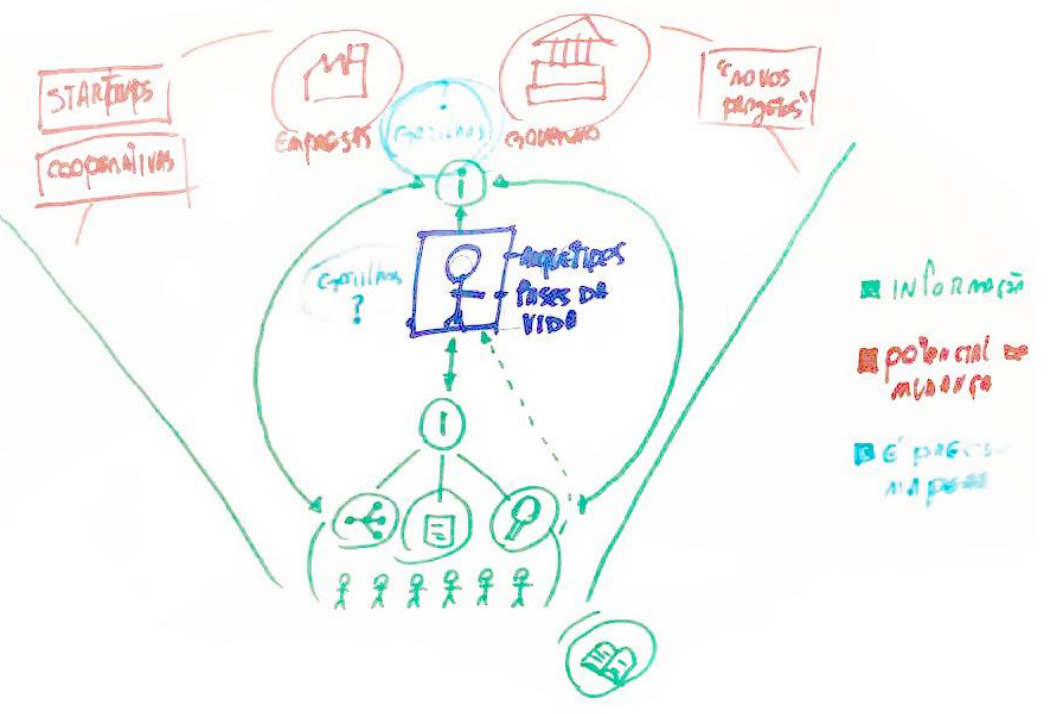

Fonte: participantes do workshop (2019)

A equipe seguiu a linha de argumentação criando um cenário com uma persona que só mudaria seu comportamento, visando a sustentabilidade, se ela fosse impactada por informações e conscientização via canais sociais que a persona acessa (via redes sociais, blogs, sites ou mesmo pessoalmente). Partindo da questão de que o tempo todo a pessoa está navegando (internet) os dados estão sendo colhidos. Neste processo a pessoa também é uma geradora e divulgadora de informação, impactando os outros reciprocamente. Quem pode produzir ações e informações para impactar a persona citada são os chamados "provedores de mudança", conforme a equipe denominou. Estes são instituições que tem potencial de promover a mudança de cenário, como empresas, governos, startups, cooperativas, entre outros, com capacidade para serem provedores de mudança e de ações de sustentabilidade. Este processo, segundo a arguição da equipe, somente é passível de acontecer se trazer vantagens para ambos os lados, indivíduos e "provedores de mudança". São os gatilhos de mudança que a equipe colocou como os pontos chave a serem explorados para realmente envolver a todos no tema, levando o grupo a refletir sobre as seguintes questões: Quais gatilhos levariam o indivíduo a serem mais receptivos a estímulos de mudança de comportamento? E quais os gatilhos levariam as empresas, governos e etc., com que eles levassem à frente projetos para a sustentabilidade?

A equipe ainda colocou o problema de que a informação não falta, o problema é o excesso dela. Como designer também é importante desenhar soluções com informações corretamente garimpadas, de maneira honesta, sem querer mascarar resultados. Outro ponto comentado foi de que, além dos provedores de mudança tradicionais, ações individuais também podem ter poder coletivo, as vezes é trazer a consciência a respeito para o "vizinho" e assim aumentar a demanda 
por soluções sustentáveis.

Quanto às questões tecnológicas foi comentado o lado do design social para reduzir as tarefas rotineiras das pessoas por meio da inteligência artificial, porém as vezes é visto como a "não inteligência", como comentado por um dos participantes. Isto ocorre quando as ferramentas tecnológicas ainda estão imaturas, causando muito ruído no processo e fazendo com que o consumidor desista daquela experiência.

A terceira RGS apresentada consta na Figura 3 a seguir e versa principalmente sobre os desafios do designer para promover o comportamento sustentável com a analogia de uma balança "na qual não se sabe qual o lado pesa mais, por exemplo, a reciclagem ou um ciclo de vida mais longo do produto? Para ser capaz de fazer este tipo de avaliação é importante que o consumidor seja sensibilizado", conforme uma das participantes pontuou. Também levantaram a questão de que não é só necessário pensar só no futuro e nas possíveis tecnologias decorrentes dele, mas olhar também para os conhecimentos ancestrais no sentido de retomar alguns hábitos que já existiam antes (low tech), buscando uma ressignificação das soluções e respeito da cultura local. Neste sentido é importante que área de tecnologia de dados também deve "converse" com as realidades de menos tecnologia e assim também poder fazer análises mais qualitativas e individuais.

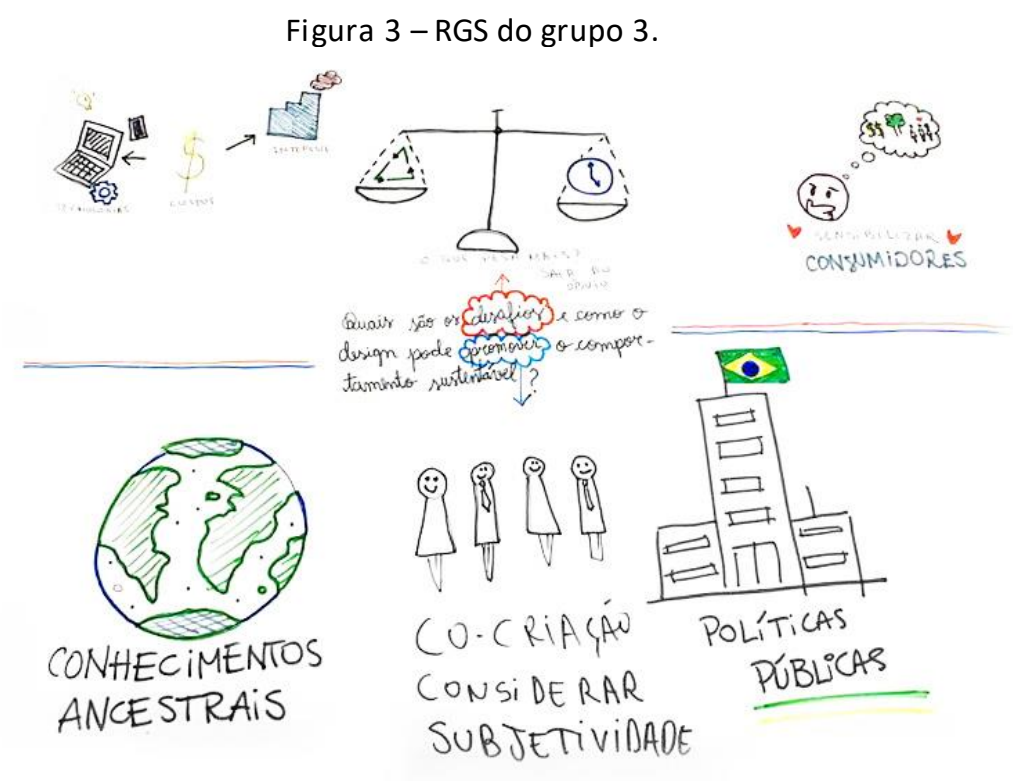

Fonte: participantes do workshop (2019)

Para a promoção do design que estimule o comportamento sustentável, os participantes deste grupo afirmaram que o processo de conscientização deve ser educativo e deve permitir a cocriação a partir de uma determinada comunidade que se interesse ou se beneficie do assunto. Além disso também consideram que a subjetividade em relação às pessoas deve ser estudada, "porque tanto o bem-estar, como o stress são relativos, cada pessoa tem uma expressão única, depende de cada indivíduo este nível comportamental", conforme uma participante. "Abraçar todas as contradições da sustentabilidade como na hora de tomar banho a pessoa pode economizar água, mas na alimentação ela não se importa", pontua outra participante. Para finalizar também citaram a relevância das políticas públicas para "puxar" a busca da sustentabilidade pelas comunidades.

\section{Discussão}

Observou-se que todos os participantes entendiam a importância do Design como influenciador de comportamentos. A artefato do grupo 1 apontou que a pessoa só mudaria seu 
comportamento, visando a sustentabilidade, se ela fosse impactada por informações de conscientização que poderia ser via canais sociais que a pessoa acessa. Nesse processo seus dados também são colhidos e a pessoa também é uma geradora e divulgadora de informação, ciclicamente o sistema se retroalimenta. Para o grupo 2, é necessário que haja gatilhos de mudança para impulsionar a mudança de comportamento. Os gatilhos são tanto do la do pessoal (consumidor), como dos provedores de mudança (instituições como empresas, governos, startups, cooperativas, entre outros). Um dos gatilhos mais óbvios pode ser via econômica, na qual a mudança de comportamento acontece ao se obter uma vantagem econômica para ambos os lados. Assim, como Bhamra et al. (2011) e Muniz e Santos (2015) pontuaram na base teórica.

Como visto no artefato do grupo 2, a integração de BigData e DfSB demanda do designer a compreensão dos fatores psicológicos necessários para a mudança, bem como para haver a manutenção do mesmo e até a possível replicação desta para a comunidade (real ou virtual. A esse respeito, os artefatos dos grupos 2 e 3 mostraram que as ações de sustentabilidade podem ter graus diferentes de aderência e impacto de acordo com o consumidor e seu comportamento. Para o consumidor ser capaz de fazer este tipo de avaliação da sustentabilidade, conforme reportaram os participantes do workshop, é importante que o mesmo seja sensibilizado quanto àquela questão. Por isso a equipe 3 defendeu que o processo de conscientização deve ser também educativo e deve permitir a cocriação, sensibilizando toda a comunidade. Tal fato provocaria a exigência de um aprofundamento comportamental perante 0 consumo que a própria fundamentação também pontuou como necessária.

Quanto à questão tecnológica que está intrinsicamente ligada a ciências dos dados e Smart Cities, a equipe 2 colocou que há ferramentas imaturas no mercado que ao invés de ajudar, são pouco intuitivas, e acabam confundindo o consumidor, prejudicando a experiência. No artefato da equipe 3 , os participantes trouxeram uma visão de olhar o futuro se inspirando nos conhecimentos e hábitos ancestrais, assim a tecnologia também pode ser ferramenta para ajudar a ressignificar as soluções já existentes, e não só criar novas soluções.

Em especial o tema das novas tecnologias digitais, dentro da ciência dos dados, foi apontado como potencial caminho para o desenvolvimento do comportamento sustentável. Os trabalhos acadêmicos levantados mostraram que ambos os caminhos, ciência de dados e sustentabilidade, são bem explorados separadamente. Porém, quando tomados em conjunto estão praticamente ausentes na literatura, reforçando as colocações de Petrini e Pozzebon (2009) e Petrinni (2006). O grupo de participantes envolvidos corroborou esta visão, comentando a falta de ferramentas e diretrizes para se trabalhar com design a partir destes dados, embora também reconheçam a potencialidade. A literatura mostrou que há muitos termos envolvidos na ciência de dados, mas que basicamente podem ser divididos em duas abordagens principais: tecnológica e administrativa. Na abordagem administrativa, por exemplo, os dados são modelados e integrados (por meio da abordagem tecnológica) para apoiar decisões estratégicas (LÓPEZ-ROBLES et al., 2019; LUCAS et al., 2016; PETRINI, POZZEBON, 2009).

Dentre as fases de um desenvolvimento de Design, um dos grupos apontou que o momento que mais a ciência de dados pode ajudar é quanto à identificação de oportunidades de novos negócios e projetos. Além desta, a literatura também apontou a falta de métricas para medir o efeito e evidencias de estratégias de DfSB (CESCHIN, GAZIULUSOY, 2016), o que também aponta outra fase na qual a ciência dos dados pode apoiar a sustentabilidade. Fora as oportunidades citadas acima, foi visto que a ciência de dados, ma is especificamente por meio do BA, pode ser usada para a segmentação de clientes atuais ou potenciais, e para avaliação de desempenho de produtos (SCHERER et al., 2016) e serviços. Assim, o desenvolvimento do artefato mostrado na equipe 1 também prevê esta aplicação. 
A questão ética quanto ao DfSB ficou em evidência na tanto nos grupos como na literatura levantada (CESCHIN, GAZIULUSOY, 2016; BHAMRA et al., 2011). Além disso o primeiro artefato desenvolvido ainda trouxe a preocupação ética no uso de dados, somada à sustentabilidade. Mostra-se aqui então que, conjuntamente, esses temas têm uma combinação que exige mais cuidados éticos ainda, já que o descuido ético de um tema pode potencializar o de outro.

\section{Considerações Finais}

O presente estudo apresenta a perspectiva de profissionais e pesquisadores acerca a relação entre as ferramentas e métodos da Era dos Dados às teorias e práticas do Design para o Comportamento Sustentável. De maneira geral confirmou-se as informações obtidas na revisão da literatura, apontando para uma demanda urgente de compreensão da interface destas duas temáticas e sua articulação em termos do desenvolvimento de competências no campo do Design.

Quanto ao método utilizado, foi adequado porque proporcionou uma oportunidade de pesquisa interdisciplinar, já que os temas necessitavam de diferentes conhecimentos. $O$ fato de ter realizado o desenvolvimento dos artefatos (RGSs) com um grupo diversificado de designers, profissionais e acadêmicos, permitiu uma rica troca de aprendizagem por parte dos pesquisadores envolvidos (contato com a realidade) e por parte dos próprios participantes (maior contato acadêmicos). O método ainda permitiu uma maior flexibilidade porque possibilita com que que os conhecimentos sejam gerados ao longo do processo. Em especial destaca-se a rapidez com que a informação foi disseminada apoiando construções intelectuais diversas a partir da mesma. 0 grupo todo, em pouco espaço de tempo, conseguiu interagir e gerar artefatos a partir da teoria apresentada, como era desejado com a proposição do workshop.

Com essas recomendações e observações até aqui, considera-se que o artigo tenha explorado uma base para estudos dentro da área, porém é necessário dar continuidade nos temas e aprofundá-los. Uma sugestão para trabalhos futuros é dar continuidade na produção dos artefatos conforme o aprofundamento teórico aconteça, assim como o próprio método de DSR prevê. Outra sugestão é quanto a avaliação das RGSs geradas para o desenvolvimento de uma única RGS que condense toda a informação até aqui, de maneira unificada. Inclusive esta RGS pode ser lapidada conforme aconteçam produções de novos artefatos sobre os mesmos temas. 0 trabalho aqui exposto teve muitas inserções acadêmicas e práticas quanto à questão ética dos temas aqui tratados. Portanto, outra recomendação futura seria aprofundar também este tema. RGSs também trazem um benefício quanto à aprendizagem colaborativa que as mesmas podem proporcionar. Quando usadas no contexto coletivo, conduzem a um foco comum entre os participantes, promovendo a interatividade e envolvimento ao estimular a colaboração e a criação de significados compartilhados, além de que estimulam uma melhor escuta e lembrança das questões discutidas. Este conjunto de imagens, palavras e formas que compõem a RGS são inclusive estimulados a serem feitos de forma coletiva à mão, com o intuito de manter o grupo envolvido e concentrado na atividade (BUENO, PADOVANI, 2017).

\section{Referências}

ANDERLE, D. F.; JUNIOR, V. F.; GAUTHIER, F. A Utilização da Tecnologia da Informação nas Smart Cities-um Estudo Bibliométrico. Instituto Federal Catarinense, sd, 2013.

BATTY, M., AXHAUSEN, K. W., GIANNOTTI, F., POZDNOUKHOV, A., BAZZANI, A., WACHOWICZ, M. ... \& PORTUGALI, Y. Smart cities of the future. The European Physical Journal Special Topics, v. 214, n. 1, p. 481-518, 2012.

BHAMRA, T.; LILLEY, D.; TANG, T. Design for sustainable behaviour: Using products to change consumer behaviour. The Design Journal, v. 14, n. 4, p. 427-445, 2011.

BUENO, J.; PADOVANI, S.; SMYTHE, K. C. A. S. Representações gráficas de síntese (RGSs): proposta 
de um modelo de avaliação. InfoDesign-Revista Brasileira de Design da Informação, v. 14, n. 2, p. 187-203, 2017.

CESCHIN, F.; GAZIULUSOY, I. Evolution of design for sustainability: From product design to design for system innovations and transitions. Design studies, v. 47, p. 118-163, 2016.

DRESCH, A.; LACERDA, D. P.; JÚNIOR, J. A. V. A. Design science res earch: método de pesquisa para avanço da ciência e tecnologia. Bookman Editora, 2015.

FIALKOWSKI, V. P. Prospecção e Gestão de Design: Busca da Inovação Guiada pelo Significado. 296f. Dissertação: Programa de Pós-Graduação em Design - Universidade Federal do Paraná, Curitiba, 2019.

LÓPEZ-ROBLES, J. R., OTEGI-OLASO, J. R., GÓMEZ, I. P., \& COBO, M. J. 30 years of intelligence models in management and business: A bibliometric review. International Journal of Information Management, v. 48, p. 22-38, 2019.

LUCAS, A.; CAFÉ, L. M. A.; VIERA, A. F. G. Inteligência de negócios e inteligência competitiva na ciência da informação brasileira: contribuições para uma análise terminológica. Perspectivas em Ciência da Informação, v. 21, n. 2, p. 168-187, 2016.

MUNIZ, M. O.; SANTOS, A. D. A Pesquisa em Design para o Comportamento Sustentável: Lacunas e Desafios. Mix sustentável, v. 1, n. 2, p. 58-67, 2015.

PADOVANI, S. Representações gráficas de síntese: artefatos cognitivos no ensino de aspectos teóricos em design de interface. Educação Gráfica, Bauru, v. 16, n. 2, p. 123-142, 2012.

PETRINI, M.; POZZEBON, M. Managing sustainability with the support of business intelligence: Integrating socio-environmental indicators and organisational context. The Journal of Strategic Information Systems, v. 18, n. 4, p. 178-191, 2009.

PRIOR, V. Glossary of terms used in competitive intelligence and knowledge management. Virginia: SCIP-Strategic and Competitive Intelligence Professionals, 2010.

ROSENMANN, C. H. B. A.; SCIAMANA, J. L.; FIALKOWSKI, V. P.; KISTMANN, V. B. Design e internet das coisas em produtos de linha branca no Brasil. In: 11을 Congresso Brasileiro de Inovação e Gestão de Desenvolvimento do Produto CBGDP, 2017, São Paulo. Anais... São Paulo: Blucher, p. 905-913.

SANTOS, A. S. Seleção do Método de Pesquisa: Guia para pós graduando em design e áreas afins. Insight, 2018.

SANTOS, A. S.; PEREZ, I. U. Ensino de moda para atuação em novos contextos de design e de produção: sustentabilidade, open design e fabricação digital. Revista de Ensino em Artes, Moda e Design, v. 1, n. 1, p. 149-174, 2017.

SCHERER J., KLOECKNER A., RIBEIRO J., PEZZOTTA G., PIROLA F. Product-Service System (PSS) design: using Design Thinking and Business Analytics to improve PSS design. Procedia CIRP Publisher: Elsevier B.V. vol: 47 pp: 341-346, 2016.

STRAUSS, L. M., JANISSEK-MUNIZ, R., BRODBECK, A. F. Inteligência competitiva, empresarial, estratégica ou de negócios? Um olhar a partir da Administração de Empresas. FACEF PesquisaDesenvolvimento e Gestão, v. 14, n. 2, 2012.

SCIAMANA, J. L; FIALKOWSKI, V. P.; KISTMANN, V. Design e Internet das Coisas para a Indústria Calçadista: perspectivas futuras. In: 14ํㅡ Colóquio de Moda, 2018, Curitiba. Anais... Curitiba: Pontifícia Universidade Católica do Paraná, 2018. p. 1-17.

VEZZOLI, C., KOHTALA, C., SRINIVASAN, A., DOS SANTOS, A., XIN, L., CHAVES, L. I., ... \& ENGLER, R. C. Sistema Produto+ Serviço Sustentável: Fundamentos. 2018. 